\title{
Development of Intelligent Decision Support System for Selection of Quality Tools and Techniques
}

\author{
M. D. Mohd Amran, A.W. Mohamad Ikbar, S. Khairanum, A. B. Fairul Anwar, and B. Rahmat Roslan
}

\begin{abstract}
This research derives systematic analysis and synthesize previous research published with aim to highlight and develop a decision aid for Quality Tools and Techniques (QTT) selection which enable practitioner make a rational and structured decision though development of Intelligent Decision Support System (IDSS). Vast numbers of QTT for problemsolving and improvement activities give a significant challenge to determine the suitable QTT. The chosen QTT affect the effectiveness of improvement activity and misused of QTT can slow down the improvement process and flawed the conclusion. The IDSS namely eCIFOD was produced by translating the QTT mapping into the SQL Union and SQL Inner Join. PHP scripts were developed to run the system and uploaded to online after the Black Box Testing show good result. A single case with a single unit of the case study research strategy was used to conduct the user acceptance testing unveil the positive feedback from the user in term of feasibility, usability, and utility. Development of empirical IDSS for selection of QTT through providing structured and intelligent decision making provides holistic decision support for practitioner to select most optimize QTT to be used for improvement purpose.
\end{abstract}

Index Terms-Intelligent Decision Support System (IDSS), Quality Tool and Technique (QTT), selection method.

\section{INTRODUCTION}

Over the last 30 years, many new management methodologies aimed at the improvement of quality have been developed [1]. According to the situation in the manufacturing sector, the issues of quality play an important role [2] in order to achieve higher profits, but at the same time the product or service meet the customer satisfaction [3]. Quality movement and its practices are an interesting topic and it also a huge topic of discussion since last few decades with various issues in past, current and as well as future issues. The quality practices apparently evolved together with the topic of discussion, but the intentions remain unchanged to ensure quality cannot be taken for granted because of the consequence of ignoring the quality can affect the reputation of the organization. The quality movement under the subject Total Quality Management and

Manuscript received August 20, 2019; revised October 11, 2019. The research reported in this paper was supported by the Short Term Research Grant (STRG) No UniKL/CoRI/str18041 awarded by Universiti Kuala Lumpur Malaysia, and Fundamental Research Grant Scheme (FRGS) No FRGS/1/2019/TK03/UNIKL/01/1 awarded by Ministry of Education Malaysia.

The authors are with the Quality Engineering Department, Universiti Kuala Lumpur, Malaysian Institute of Industrial Technology, Johor Bahru, Johor, Malaysia (e-mail: mamran@unikl.edu.my, mikbar@unikl.edu.my, fairulanwar@unikl.edu.my, rahmatroslan@unikl.edu.my).
Business Excellence, found the increasing trend of the article's publication related to management techniques and tools from 1987 to 2011 [4]. They also found that the amount of research in 2002-2011 is significantly higher than that in the first decade 1987-1996. The findings somehow tally with the result from the Scopus search engine as per Fig. 1. By using few keyword downloaded, there is a huge number of documents found in the Scopus search engine. When arranging the number of documents based on a yearly basis, there is increasing trend from 1971 until 2017 which indicate the important and significant to the industries especially organization which eager to adopt improvement.

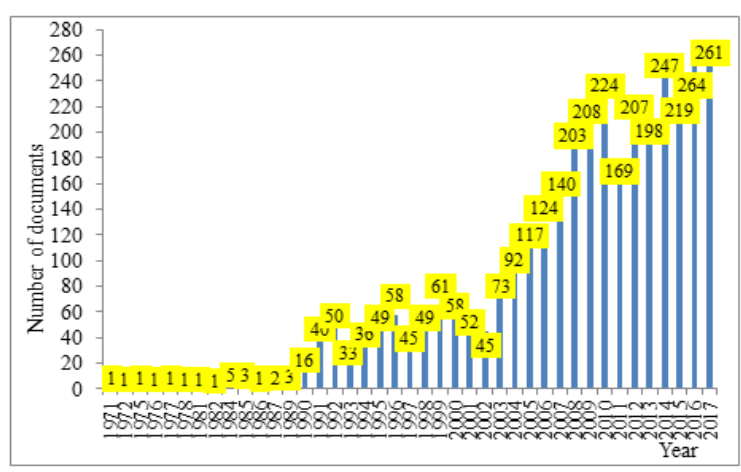

Fig. 1. Studies related to Quality Tools and Techniques (QTT).

\section{SELECTION OF QTT}

Quality cannot be obtained consistently by coincidence, but through designated improvement. The quality improvement methodology is based on the improvement of systems and processes through a variety of tools and techniques [5], [6]. Publications in general management and strategic decision-making have urged managers to employ a rational decision-making process, when considering the adoption of new improvement.

\section{A. Selection Dilemma}

In order to support, develop and advance a process of continuous improvement, it is necessary for an organization to select appropriate tools and techniques [7]. This is important because the chosen QTT can affect the effectiveness of improvement activity. The QTT can be very effective and also can be very ineffective and affect the improvement process. Misused of QTT can slow down the process and flawed the conclusion [8]. It is very important to know which QTT to be used in improvement activities [9]. However, selection of the most appropriate tools has been always not easy due to a huge number of QTTs available [9], [10].

Vast amount of QTTs will create difficulty for the user to choose the most appropriate QTT during problem-solving 
and improvement activity. Therefore, there is a need to find a proper solution to help the user to ease the selection of QTTs. There are many materials such as books and articles to describe the QTTs. However, to understand each QTT by looking to each material will require a lot of time to finish. Typical instrument to help the user to select proper tools is using a matrix diagram. Usually, the selection of QTTs was influenced by the knowledge of the user. The knowledge gain by them typically obtains through experience and training. The content of the training usually will explain the how and when to use QTTs. However, to attend the training some investment is required and the more training, the more investment needed [11], [12]. The investment cost is a factor to choose the QTT and the cost included training the people to use the tool, cost to employ consultants to implement the QTT successfully and sometimes require the cost to buy supporting software to use the QTTs [13]. On the other hand, the experiences of user help them to choose the right purpose of QTT in order to ensure the effectiveness of QTTs. [14] have identified that the results from the application of a particular QTTs are relying heavily on the skill and experience of those implementing it.

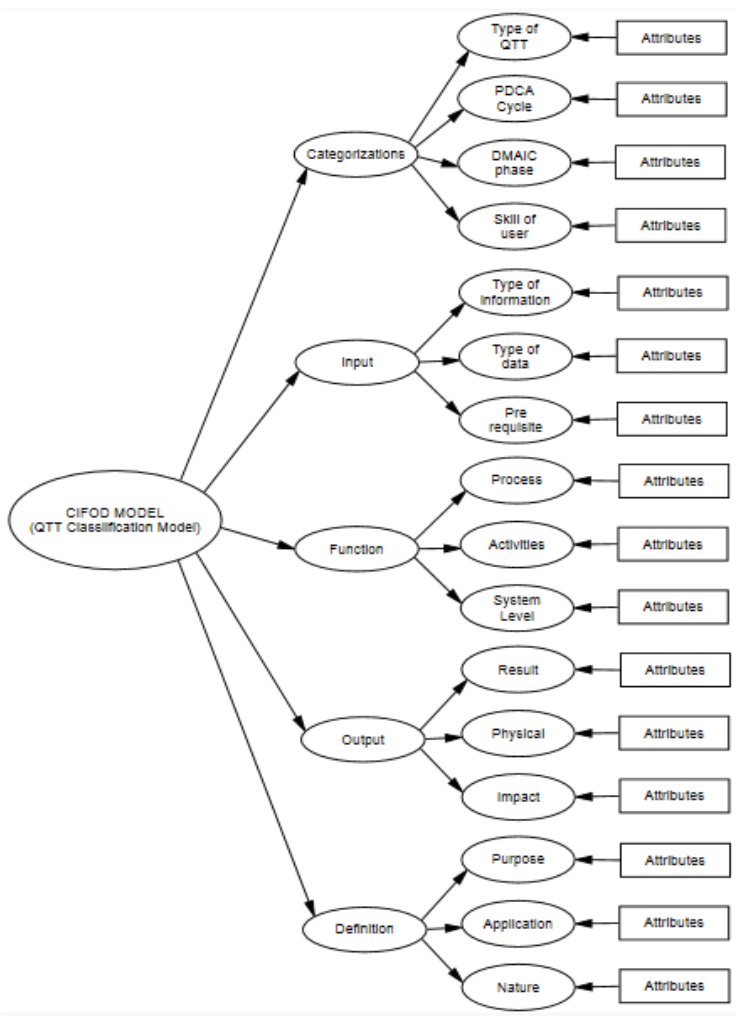

Fig. 2. CIFOD model.

\section{B. Selection of Attribute for QTT}

Apparently, the selection of QTTs is depending on the user's knowledge and this knowledge is considered as the information that able to define the QTTs to help the user choose the QTTs. Exploring the body of knowledge of QTTs is able to classify them into specific attributes that help the user to understand QTT in a wider perspective. In this study, the information was obtained via comprehensive literature and input from quality practitioners that involved in Team Excellence (TE) Convention organized by Malaysia Productivity Corporation (MPC). From comprehensive data analysis through the Confirmatory Factor Analysis and Expert Opinion, the concluded attributes of QTT were established and can be used to well define the QTTs

The classification of QTT's attributes will help to sort the attributes in a more organized arrangement and easy to understand. In this study, the classification is referred as the outcome of grouping the QTT's attributes into logical categories. The classification of these attributes is illustrated in Fig. 2 that also known as CIFOD Model. CIFOD is the acronym of those 5 main groups namely Categorization, Input, Function, Output and Definition that consist of 16 subcategories and 140 attributes.

TABLE I: EXAMPLE OF QTT MAPPING

\begin{tabular}{|c|c|}
\hline Attributes $\quad$ QTT & Ishikawa Diagram \\
\hline \multicolumn{2}{|r|}{ Categorization } \\
\hline Type of QTT & Basic QTT, Analytical QTT \\
\hline $\begin{array}{l}\text { Place of QTT in PDCA } \\
\text { cycle }\end{array}$ & Plan \\
\hline $\begin{array}{c}\text { Place of QTT in DMAIC } \\
\text { phase }\end{array}$ & $\begin{array}{l}\text { Define (D), Measure (M), Analyse (A), } \\
\text { Improve (I) }\end{array}$ \\
\hline $\begin{array}{c}\text { Skill or experience of } \\
\text { user }\end{array}$ & Novice \\
\hline \multicolumn{2}{|r|}{ Input } \\
\hline $\begin{array}{l}\text { Type of information } \\
\text { needed }\end{array}$ & Process knowledge \\
\hline Type of input data & Non-numerical \\
\hline $\begin{array}{l}\text { Prerequisite QTT require } \\
\text { before using the QTT }\end{array}$ & No \\
\hline \multicolumn{2}{|r|}{ Output } \\
\hline Result produced & Classifies, organises, prioritizes \\
\hline Physical result generated & Diagram \\
\hline Impact on quality & Long term \\
\hline \multicolumn{2}{|r|}{ Definition } \\
\hline Purpose of QTT & $\begin{array}{l}\text { Grouping, visualizing, generates, } \\
\text { analysing, showing, and identifying }\end{array}$ \\
\hline Application of QTT & $\begin{array}{l}\text { Showing relations, structuring ideas, } \\
\text { understanding and analyzing the problems } \\
\text { and process, problem solving, and } \\
\text { identifies waste }\end{array}$ \\
\hline Nature of QTT & Tool \\
\hline \multicolumn{2}{|r|}{ Function } \\
\hline $\begin{array}{l}\text { Process to implement } \\
\text { QTT }\end{array}$ & $\begin{array}{l}\text { Market research, control and measure, } \\
\text { storage, engineering services, } \\
\text { manufacturing process, product designing, } \\
\text { sales, technical preparation of production, } \\
\text { product utilization, purchasing, customer } \\
\text { services, company-wide, and healthcare }\end{array}$ \\
\hline Activity requires QTT & $\begin{array}{l}\text { Supplier improvement activities, process } \\
\text { control activities, process improvement } \\
\text { activities, internal customer focus } \\
\text { activities, external customer focus } \\
\text { activities, reporting activities, } \\
\text { measurement activities, inspection } \\
\text { activities, leadership activities, quality } \\
\text { system activities, participation activities, } \\
\text { recognition activities, education activities, } \\
\text { training activities, consultation activities, } \\
\text { management of processing activities, and } \\
\text { performance of processing activities }\end{array}$ \\
\hline System level & $\begin{array}{l}\text { Company, outbound supply chain, inbound } \\
\text { supply chain, plant, hospital, department, } \\
\text { line, cell, and job }\end{array}$ \\
\hline
\end{tabular}

CIFOD model represents the collective classification of QTT's characteristic with various attributes that will be used for the QTT selection. The wide-range of QTT's background of this model give an opportunity to practitioner to select the QTT within their knowledge and need. Thus, this model apparently can help the practitioner that has limited experience and knowledge on the QTT. Subsequenly, the attributes in CIFOD model were used as an input in the web-based intelligent decision support system for QTT 
selection that will help the user to choose the most appropriate QTTs even in the large amount of QTTs.

\section{QTT Mapping}

QTT mapping is the action of identifying and matching the characteristic of QTT with the attributes in the CIFOD model. The QTT mapping is conducted by using Consensus Group Techniques [15] that consist of 13 experts from academics and industrial practitioners. From this method, this study found that 140 attributes were able to map with 45 QTTs and the consensus able to reach above $75 \%$ for each QTT mapping although the experts are from different fields such a manufacturing industries, service sector and government agencies.

Hence, the attributes found in this study were proven as the identity or characteristic of the QTT. Table I show the characteristics of Ishikawa diagram based on the QTT's attributes that was found during the QTT mapping.

The findings from QTT mapping is translated into a table form. The attributes that belong to the QTT was marked as 1 and if not was marked as 0. The QTT mapping table was used for set up the SQL database.

\section{Selection Method for QTT}

Generally, if the decision is made using a typical method such as through a discussion (collection of opinion and experience) or using the reading materials (e.g. books and journals) can be called as a manual decision. The CIFOD model with the QTT mapping in the matrix or table format, if used as a decision-making tool, is also identified as a manual decision method. Therefore, the manual method basically refers to either to refer a specific diagram or use a matrix to choose the QTT and computerized method can be reffered as system selection method with support from any computer technology such an IDSS.

There are 4 references found that discussed on the method of QTT selection exclusive the typical selection method through DMAIC phases or PDCA cycle. From these references, there are two types of selection, either manually selects the QTT or by using the system to select the QTT. The content of theses QTT selection methods mainly uses the attributes of QTT as selection criteria. Table II shows the type of selection found in each reference. The selection method using DSS is apparently much better to compare to manual searching as this system is able to reduce the selection time and able to compile the result in an informative way such as using graphic and percentage. However, both references that use DSS as a selection method did not provide any empirical evidence on the effectiveness of the system in selecting the correct QTT during improvement and problem-solving activities.

\begin{tabular}{|} 
TABLE II: THE SELECTION METHOD FROM PREVIOUS REFERENCES \\
\begin{tabular}{|c|c|c|}
\hline No & Authors & Type Of Selection \\
\hline 1 & $\begin{array}{c}\text { Pavnaskar, Gershenson and } \\
\text { Jambekar (2003) }\end{array}$ & Manual (Using Diagram) \\
\hline 2 & $\begin{array}{c}\text { Hagemeyer, Gershenson and } \\
\text { Johnson (200) }\end{array}$ & Manual (Using Matrix) \\
\hline 3 & Chen (2009) & Computerized (DSS) \\
\hline 4 & Starzyńska and Hamrol (2013) & Computerized (DSS) \\
\hline
\end{tabular}
\end{tabular}

\section{DEVELOPMENT OF ECIFOD}

This research focused on the development of Intelligent Decision Support System (DSS) that physically translated the CIFOD model with the QTT mapping to a computerbased system with a web-based format. The physical output of this phase is a new product so-called eCIFOD

A system that integrates the knowledge from experts is known as Knowledge-Based Decision Support System (KBDSS) or Intelligent Decision Support System (IDSS) [16]. Thus, the word intelligent basically refers to the knowledge-based that fundamentally reflects the content of QTT mapping that was developed in the previous phase. From this highlight, this study adapted similar terminology which is Intelligent Decision Support System (IDSS) as a computer-based information system to support decision making in selecting the appropriate QTT for improvement and problem-solving activities.

Several processes of software development were conducted in this phase such as designing the algorithm and setting up the SQL database. The prefix e- is used as an indication of web-based IDSS. The web-based IDSS refers to a computerized system that delivers decision support information or tools to a decision maker or analyst using a web browser such as Internet Explorer or Mozilla Firefox [17]. There are five types of IDSS namely data-driven, model-driven, knowledge-driven, document-driven, and communications driven and all of these types of IDSS can be implemented using web-based technologies [17].

\section{A. PHP Script}

Since this study used web-based IDSS, the PHP scripting language is used to transform the CIFOD to eCIFOD. PHP was designed for web page creation and primarily coded in $\mathrm{C}$ as a scripting language. The scripting language is designed to communicate instructions to a computer and the server. It is a set of instructions that used to produce the desired output. The PHP script language was created to develop the instruction to the server and to develop the interface for clients.

Since the database involved, the Structured Query Language (SQL) is used as the primary standard for database languages. The most well-suited Database Management System (DBMS) to working with PHP is MySQL. MySQL is an open source DBMS that mainly used on the web and the systems that run on the server. To administrate the MySQL, this study used phpMyAdmin software as an administration tool for MySQL.

Finally, there were 22 main PHP files created to develop the eCIFOD. 11 files created as input to the system that used to select the attribute of QTT and 11 files created as an output from the system to list out the QTT based on the selected attributes. The eCIFOD was designed to find the QTT in a single classification or combined all classification in one group namely 'expert'. However, the combined classification to find the QTT was designed only in the inner join command as this command is a specific search to the specific identity of QTT based on the attributed selected. Table III tabulated the PHP files created based on the CIFOD classification and the SQL searching method namely union and inner join. Fig. 3 mapped the files created with the logical flowchart of eCIFOD. 
TABLE III: PHP FILE CREATED TO DEVELOP ECIFOD

\begin{tabular}{|c|c|c|c|c|}
\hline Classification of QTT & \multicolumn{2}{|c|}{ Union } & Inner join \\
\hline & Input & Output & Input & Output \\
\hline Categorization & search3.php & search4.php & search-innerjoin.php & search-innerjoinresult.php \\
\hline Input & inputsearch.php & inputresult.php & inputsearchinnerjoin.php & inputresultinnerjoin.php \\
\hline Function & functionsearch.php & functionresult.php & functionsearchinnerjoin.php & functionresultinnerjoin.php \\
\hline Output & output3.php & output4.php & outputsearchinnerjoin.php & outputresultinnerjoin.php \\
\hline Definition & Definitionsearch.php & Definition.php & Definitionsearch-innerjoin.php & Definition-result-innerjoin.php \\
\hline Overall (Expert) & N/A & N/A & qttfullinnerjoin.php & qttfullinnerjoinresult.php \\
\hline
\end{tabular}

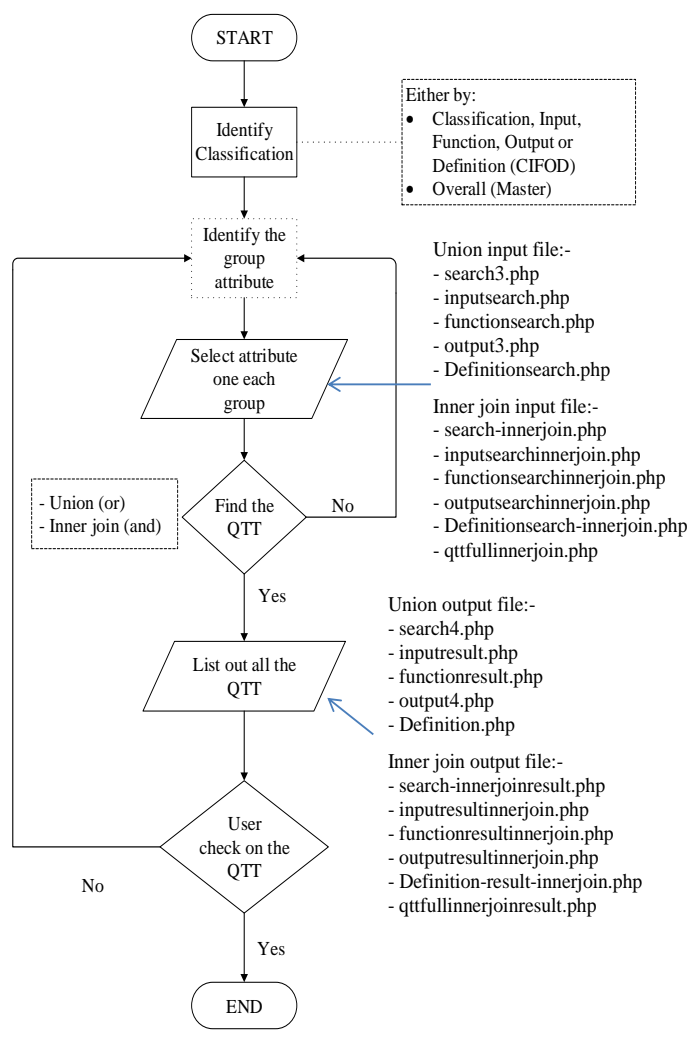

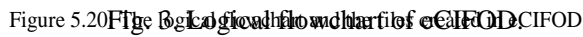

\section{B. SQL Database}

The database was first set up prior to creating the input and output PHP program files. Fig. 4 shows the view of the general setup of the database based on each construct and overall attributes, namely qttfull, as well as the view of QTT mapping in the database.

This research created 12 PHP files for this preference as shown in Table IV, either based on the attributes in each classification or based on the full list of attributes. There were 6 files to get the overall table of QTT mapping and 6 files to visualize single QTT with its attributes.

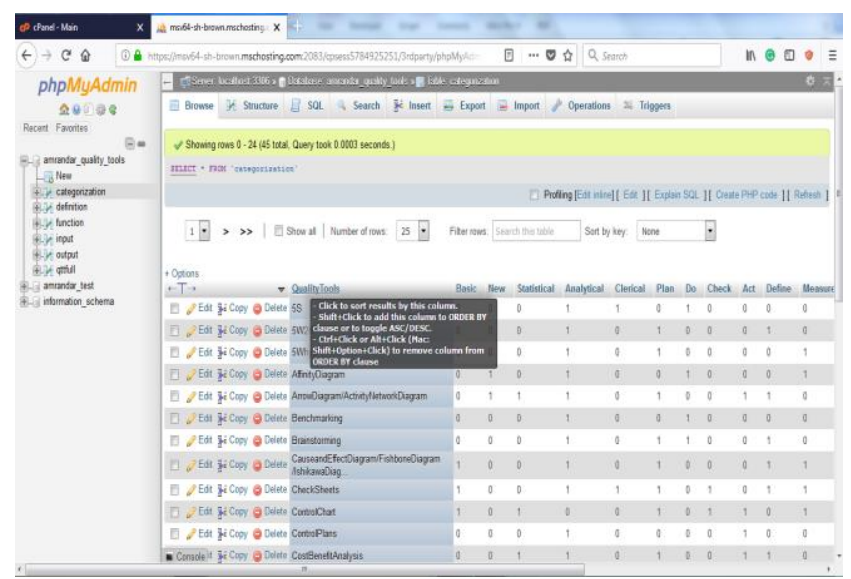

Fig. 4. General setup of the database.

\begin{tabular}{|c|c|c|}
\hline \multirow{2}{*}{ Classification of QTT } & \multicolumn{2}{|c|}{ Master Select } \\
\hline & Overall QTT & Single QTT \\
\hline Categorization & categorizationl.php & categorization2.php \\
\hline Input & Input2.php & Input3.php \\
\hline Function & functionl.php & function2.php \\
\hline Output & outputl.php & output2.php \\
\hline Definition & Definitionl php & Definition2.php \\
\hline Overall (Expert) & Viewfullmaster.php & Viewfullresult.php \\
\hline
\end{tabular}

Table V shows the important source code for union structure and Table VI for inner join structure, that are taken from one of the construct (i.e. Categorization) that used in the PHP script to make the program (i.e. eCIFOD) able to produce the lists of QTT based on selected attributes.

The input files in the union and inner join mainly use the multiples checked checkboxes operation to find the QTTs based on the user selections. Meanwhile, the output files for both union and inner join were mainly used SQL query operation to match the selection with the data in the SQL database.

The difference between union and inner join for eCIFOD is the union will list out all the QTT that related to the selected attributes, meanwhile, the inner join will consider the selected attributes as the specific identity of the QTT and list out the QTT that match with the identity. For example, if the user selects 'Basic' and 'New' in the Categorization checkboxes, the output of union will list out 14 QTTs that refer to 7 basic quality tools and 7 new quality tools. In the inner join, if the user selects 'Basic' and 'New', the output will be nothing because there is no QTT that is considered as basic and new quality tools at the same time.

TABLE V: EXAMPLE OF SQL SOURCE CODE UNION Name Page: Search4.php

Query: \$query_RecordsetQTT

Database Name: qualitytools

Classification Name: Categorization

Echo/Sample \$QTT1, \$QTT2, \$QTT3, \$QTT4, \$QTT5 Column:

\section{HEADER/END;}

\section{$<$ ?php do $\{$ ? $><\mathrm{td}><$ ?php echo}

\$row_RecordsetQTT['qualitytools']; ?>\&nbsp; </td $><$ ?php \} while

$($ Srow_RecordsetQTT $=$ mysql_fetch_assoc $($ RecordsetQTT) $)$; ?>

$$
\text { UNION CODE: }
$$

Function explanation;

//SELECT 'Database Name` FROM `Classification Name`A WHERE

A. 'Column Name` = 'Y' UNION SELECT 'Database Name` FROM

'Classification Name` B WHERE B. Column Name ' $=$ ' $\mathrm{Y}$ ' Echo CODE; Function explanation;

//echo \$Column Name1. "==" . \$Column Name2. "==" . \$Column

Name3. "==" . \$Column Name4. "==" . \$Column Name5. "=="; ACTUAL from PAGE;

NO 1; //SELECT `qualitytools` FROM `categorization`A WHERE

A. 'type1.basic' = 'Y' UNION SELECT `qualitytools` FROM 'categorization ' B WHERE B. 'type2.new' = 'Y' 


\begin{tabular}{|c|}
\hline Echo Function; \\
\hline $\begin{array}{l}\text { NO 2; //echo \$QTT1. "==" . \$QTT2. "==" . \$QTT3. "==" . \$QTT4. } \\
\text { "==" . \$QTT5. "=="; }\end{array}$ \\
\hline $\begin{array}{l}\text { UNION CODE STRUCTURE } \\
\text { Start Union Code for Column No } 1 . \\
\text { Name of Column No } 1 \text { = basic }\end{array}$ \\
\hline $\begin{array}{c}\text { if }(\$ Q T T 1<>\text { NULL })\{\text { \$query_RecordsetQTT }=\text { "SELECT qualitytools } \\
\text { FROM categorization WHERE 'basic” = “. \$QTT1; }\}\end{array}$ \\
\hline Function explanation; \\
\hline 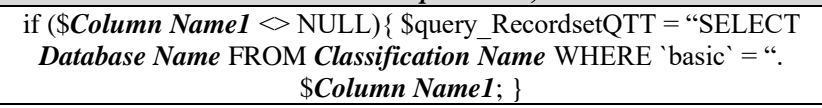 \\
\hline
\end{tabular}

\section{Black Box TESTING RESUlt}

In order to validate the functionality of the decision support system, the Black Box Testing was used in this research. Functional requirements define what the system must do where the system will apply logic to an input and produce the required output. Thus, the test was conducted to ensure the PHP script produces the correct output and to eliminate any bugs. The test was conducted to the final version of eCIFOD and total 34 tested were conducted in Black Box Testing. Table VII shows the main result of Black Box Testing of eCIFOD. The result of Black Box Testing shows that all tested were passed, thus the scripts were able to produce the desired output as instructed in the PHP script.

The holistic case study design was used to test the application of eCIFOD in the actual phenomenon. The eCIFOD was used to support the improvement team to select the QTT in order to reduce the defective percentage from 7\% to 3. 9 QTTs were adopted from eCIFOD, namely Gantt Chart, Affinity Diagram, Prioritization Matrix, Check Sheet, Ishikawa Diagram, Brainstorming, Pareto Chart, Graph and Matrix Diagram. The improvement was successfully conducted within 3 months.

\section{USER ACCEPTANCE TESTING}

The User Acceptance Testing (UAT) was conducted to measure the applicability of eCIFOD. 3 types of quality attributes or criteria adopted from Microsoft Application Architecture Guide with total 10 measurements were used to measure the user acceptance level. The result shows the user acceptance level is 3 and above, indicate that the eCIFOD meet the user requirement and able to support the improvement team to select suitable QTTs during the improvement activities.

Case study research strategy was adopted to test the eCIFOD in actual application. A single case study that refers to Company $\mathrm{X}$ with a single unit of analysis that refers to the improvement team was chosen to test the eCIFOD. The improvement project was successfully implemented by the improvement team with the support of eCIFOD. 11 QTTs were adopted in the improvement projects that selected by using the eCIFOD. This result shows that the attributes of QTT's characteristic through eCIFOD was able to support the user to choose the right QTT for improvement activities. In the selection of QTT through eCIFOD, from 11 QTT, 10 QTTs were selected by using full search Inner Join function. It shows that the user needs to find the QTT based on specific attributes that come from a combination of several attributes from various classifications.

TABLE VI: EXAMPLE OF SQL SOURCE CODE INNER JOIN

Name Page: Search-innerjoinresult.php

Query: \$query_RecordsetQTT \$query_RecordsetQTTb

Database Name: qualitytools Z.QualityTools

Classification Name: Categorization

Echo/Sample \$QTT1, \$QTT2, \$QTT3, \$QTT4, \$QTT5 Column:

\begin{tabular}{|c|c|c|c|}
\hline HEADER/END; \\
\hline$<$ ?php do $\{$ ? $>$ \\
$\langle$ td $><$ ?php echo \$row RecordsetQTT['qualitytools']; ? $>$ \&nbsp; $</$
\end{tabular}
$<$ ?php \} while (\$row_RecordsetQTT = mysql_fetch_assoc(\$RecordsetQTT)); ?> QUERY CODE BUILD;

\begin{tabular}{|c|}
\hline QUERY CODE BUILD; \\
\hline $\begin{array}{c}\text { \$query_RecordsetQTT = "SELECT Z.QualityTools FROM } \\
\text { categorization Z"; }\end{array}$ \\
\hline $\begin{array}{l}\text { INNER JOIN CODE: } \\
\text { Function explanation; }\end{array}$ \\
\hline $\begin{array}{c}\text { if (\$QTT1 〈> NULL) \{ \$query_RecordsetQTT.= ", Classification } \\
\text { Name A"; \$query_RecordsetQTTb.= " AND A.'Basic' = ". \$Column } \\
\text { Name1. " AND A.Database Name = Z.Database Name"; }\}\end{array}$ \\
\hline $\begin{array}{c}\text { Echo CODE; } \\
\text { Function explanation; }\end{array}$ \\
\hline $\begin{array}{l}\text { //echo \$Column Name1. "==" . \$Column Name2. "==" . \$Column } \\
\text { Name3. "==" . \$Column Name4. "==" . \$Column Name5. "=="; }\end{array}$ \\
\hline ACTUAL from PAGE; \\
\hline $\begin{array}{l}\text { NO 1; if (\$QTT1 <> NULL) \{ \$query_RecordsetQTT.= ", } \\
\text { categorization A"; \$query_RecordsetQTTb.= " AND A. 'Basic` = ". } \\
\text { \$QTT1 . " AND A.QualityTools = Z.QualityTools"; }\}\end{array}$ \\
\hline Echo Function; \\
\hline $\begin{array}{l}\text { NO 2; //echo \$QTT1. "==" . \$QTT2. "==" . \$QTT3. "==" . \$QTT4. } \\
\text { "==" . \$QTT5. "=="; }\end{array}$ \\
\hline $\begin{array}{l}\text { INNER JOIN CODE STRUCTURE } \\
\text { Start Union Code for Column No } 1 . \\
\text { Name of Column No } 1=\text { basic }\end{array}$ \\
\hline $\begin{array}{c}\text { if (\$QTT1 <> NULL) \{ \$query_RecordsetQTT.= ", categorization A"; } \\
\text { \$query_RecordsetQTTb.= " AND A.'Basic` = ". \$QTT1 . " AND } \\
\text { A.QualityTools = Z.QualityTools"; }\}\end{array}$ \\
\hline Function explanation; \\
\hline $\begin{array}{c}\text { if (\$Column Name1 <> NULL) \{ \$query_RecordsetQTT.=", } \\
\text { Classification Name A"; \$query_RecordsetQTTb.= " AND A.`Basic } \\
=\text { ". \$Column Name1 . " AND A.Database Name = Z.Database } \\
\text { Name"; }\end{array}$ \\
\hline
\end{tabular}

TABLE VII: SUMMARY RESULT OF BLACK BOX TESTING

\begin{tabular}{|c|c|c|c|c|c|}
\hline $\begin{array}{l}\text { Test } \\
\text { No. }\end{array}$ & Test name & $\begin{array}{l}\text { Function Being } \\
\text { Tested }\end{array}$ & Expected Result & $\begin{array}{c}\text { Status } \\
\text { (Pass/ Fail) }\end{array}$ & Description \\
\hline 1. & $\begin{array}{l}\text { QTT mapping under } \\
\text { Categorization }\end{array}$ & $\begin{array}{l}\text { QTT mapping } \\
\text { table }\end{array}$ & $\begin{array}{l}\text { Table of QTT mapping as in a } \\
\text { database }\end{array}$ & Pass & $\begin{array}{c}\text { List of QTT with the mark as ' } 1 \text { ' and } \\
\text { ' } 0 \text { ' that similar in the database }\end{array}$ \\
\hline 3. & $\begin{array}{l}\text { Union function under } \\
\text { Categorization }\end{array}$ & $\begin{array}{l}\text { Checked } \\
\text { checkboxes }\end{array}$ & $\begin{array}{l}\text { All } 17 \text { checked checkboxes } \\
\text { can be ticked. }\end{array}$ & Pass & The ' $\checkmark$ ' appeared \\
\hline 4. & $\begin{array}{l}\text { Union function under } \\
\text { Categorization }\end{array}$ & $\begin{array}{l}\text { 'Find' button } \\
\text { hover }\end{array}$ & $\begin{array}{l}\text { Once clicked, it links to the } \\
\text { result page }\end{array}$ & Pass & $\begin{array}{l}\text { Result page show list of QTTs in a } \\
\text { table form and show number of QTTs } \\
\text { (records) found. }\end{array}$ \\
\hline
\end{tabular}




\section{CONCLUSION}

This study produced an independent process of QTT selection by using IDSS namely e-CIFOD, that was developed through comprehensive CIFOD Model and was tested in actual improvement practice. The e-CIFOD is foreseen can avoid bias because it can be used without heavily rely on the experience worker or influence by the popularity of certain QTT.

In addition, this study able to provides comprehensive guidelines for practitioner and researcher in term of selecting the most appropriate QTT to be used for problem solving and improvement activities. Improving the quality of processes and maintaining acceptable levels of performance quality are critical factors in the success of any organization and remain competitive [13].

Future research can explore the application of Artificial Intelligence (AI) such as an Artificial Neural Network and Fuzzy Logic, in the developing the QTT selection and use the attributes of QTT as the variable of measurement. The new equation may arise from this approach to find the QTT from the variables.

\section{ACKNOWLEDGMENT}

Special thanks to supervisor Prof Dato Dr Khairanum Binti Subari for valuable idea and contribution to this research. Also to corresponding author, Mr Ikbar, Dr Fairul Anwar and Mr Rahmat for review and provide assistance while completing this research.

\section{REFERENCES}

[1] N. Thawesaengskulthai and J. D. T. Tannock, "Pay-off selection criteria for quality and improvement initiatives," International Journal of Quality \& Reliability Management, vol. 25, no. 4, pp. 366-382, 2008.

[2] A. W. M. Ikbar et al., "Six sigma applications: Enhancement sigma level towards quality improvement at automative company," Advanced Materials Research, pp. 1780-1784, 2014.

[3] M. Ikbar, A. W. Mazlan, A. M. Amran, M. D. Ishamuddin, M. F. Anwar, and A. N. A. Zanariah, "Press machine process improvement by using DOE method ARPN," Journal of Engineering and Applied Sciences, vol. 11, issue 14, pp. 8598-8602, 2016.

[4] S. M. Dahlgaard-Park, C. K. Chen, J. Y. Jang, and J. J. Dahlgaard, 2013, "Diagnosing and prognosticating the quality movement - a review on the 25 years quality literature (1987-2011)," Total Quality Management and Business Excellence, vol. 24, no. 1-2, pp. 1-18.

[5] R. Millar, "Framing quality improvement tools and techniques in healthcare: The case of improvement leaders' guides," Journal of Health Organization and Management, vol. 27, no. 2, pp. 209-224, 2013.

[6] A. W. M. Ikbar, S. Khairanum, M. D. M. Amran, A. B. F. Anwar, and B. R. Roslan, "Systematic literature review of decision support model for Improvement initiatives selection," Journal of Fundamental and Applied Sciences, vol. 10, no. 6S, pp. 1093-1107, 2018.

[7] B. G. Dale and P. Shaw, Managing Quality, 3rd ed., Blackwell Publishers, Oxford, 1999.

[8] C. Hagemeyer, J. K. Gershenson, and D. M. Johnson, "Classification and application of problem solving quality tools: A manufacturing case study," The TQM Magazine, vol. 18, no. 5, pp. 455-483, 2006.

[9] M. Soković, J. Jovanović, Z. Krivokapić, and A. Vujović, "Basic quality tools in continuous improvement process," Journal of Mechanical Engineering, vol. 55, no. 5, pp. 1-9, 2009.

[10] F. Aqlan and L. Al-Fandi, "Prioritizing process improvement initiatives in manufacturing environments," International Journal of Production Economics, vol. 196, pp. 261-268, 2018.

[11] R. Seleme et al., "Six Sigma tool selection to achieve goals in the short-term-a case study," International Journal of Business Performance Management, vol. 19, no. 4, pp. 408-426, 2018.
[12] B. Starzyńska, F. Górski, and P. Buń, "Virtual reality system for learning and selection of quality management tools," in Proc. World Conference on Information Systems and Technologies. Springer, Cham, 2018, pp. 264-274.

[13] C. W. Thia, K. H. Chai, J. Bauly, and Y. Xin, "An exploratory study of the use of quality tools and techniques in product development," The TQM Magazine, vol. 17, no. 5, pp. 406-424, 2005.

[14] M. Spring, R. McQuater, K. Swift, B. Dale, and J. Booker, "The use of quality tools and techniques in product introduction: An assessment methodology," The TQM Magazine, vol. 10, no. 1, pp. 45-50, 1998

[15] D. List, "The consensus group technique in social research," Field Methods, vol. 13, no. 3, pp. 277-290, 2001.

[16] J. E. Aronson, T. P. Liang, and E. Turban, 2005, Decision Support Systems and Intelligent Systems, Pearson Prentice-Hall.

[17] D. J. Power, "Web-based and model-driven decision support systems: Concepts and issues," AMCIS 2000 Proceedings, p. 387, 2000.

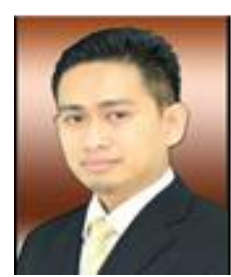

M. D. Mohd Amran received a bachelor of engineering in chemical and master of management in technology from Universiti Teknologi Malaysia in 1999 and 2008, and obtained a PhD in manufacturing engineering from Universiti Kuala Lumpur. He is currently working as a senior lecturer at the Quality Engineering Department, and appointed as the head of research and innovation at Universiti Kuala Lumpur, Malaysian Institute of Industrial Technology. His research interest includes the decision support system, lean six sigma and lean healthcare.

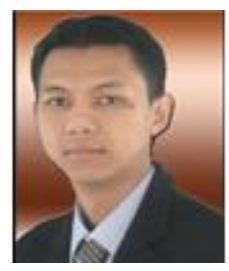

A. W. Mohamad Ikbar is currently working as a senior lecturer at the Quality Engineering Department, Universiti Kuala Lumpur, Malaysian Institute of Industrial Technology. He had received a bachelor of mechanical engineering in industrial and master of industrial engineering from Universiti Teknologi Malaysia in 2009 and 2011. His research interest includes the decision support system, advance manufacturing and industrial engineering.

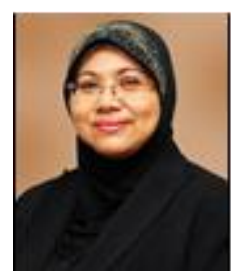

S. Khairanum obtained her bachelor science in physics and master degree science in physics from Indiana State University, USA in 1984 and 1987. In 1994 she obtained a $\mathrm{PhD}$ in mechanical \& manufacturing engineering from University of Birmingham, UK. She is currently working as a professor and deputy vice chancellor at Universiti Kuala Lumpur, Malaysia. Her research interest includes the quality engineering related and advance

manufacturing

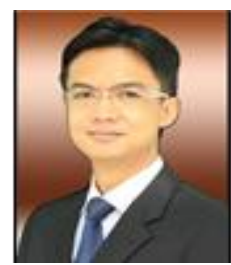

A. B. Fairul Anwar is currently working as a senior lecturer at the Quality Engineering Department, Universiti Kuala Lumpur, Malaysian Institute of Industrial Technology. He had received a bachelor degree in science (mathematics industry) and master of management (technology) from Universiti Teknologi Malaysia in 2002 and 2009, and obtained a $\mathrm{PhD}$ in manufacturing engineering from Universiti Kuala Lumpur. His research interest includes the optimization, lean six sigma and lean healthcare.

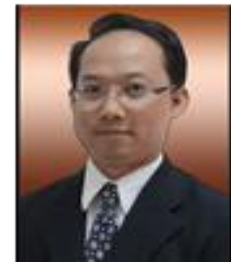

B. Rahmat Roslan is currently working as a lecturer at the Quality Engineering Department, Universiti Kuala Lumpur, Malaysian Institute of Industrial Technology. He had received a bachelor of engineering in electrical \& electronics) from Universiti Putra Malaysia in 1999 and master of management in technology from Universiti Teknologi Malaysia in 2015. His research interest management and lean healthcare. 